\title{
Energy efficiency: how far does it get us in controlling climate change?
}

\author{
Diana Ürge-Vorsatz $\cdot$ Bert Metz
}

Published online: 17 March 2009

(C) Springer Science + Business Media B.V. 2009

\section{The mitigation challenge}

The Fourth Assessment Report (AR4) of the Nobel Peace Prize-winning Intergovernmental Panel on Climate Change (IPCC) has served as a landmark document to influence humanity's battle against climate change. It was the AR4 that first declared that there is a "very high confidence" that "the global average net effect of human activities" since the industrial revolution "has been one of warming", and that warming of the climate system is by now "unequivocal"(IPCC 2007a). In addition, it established that most of the observed increase in global average temperatures in the last five decades is very likely due to anthropogenic influence, i.e. to the observed human-caused increase in greenhouse gas concentrations.

Depending on the rate of change in greenhouse gas emissions, global mean temperature will continue to rise between $1^{\circ} \mathrm{C}$ and $6^{\circ} \mathrm{C}$ as compared to $1990-2000$ levels (IPCC 2007a). The IPCC AR4 and several other studies published thereafter have clearly demonstrated that with warming of several degrees above current levels, dramatic ecological, agricultural, economic and social damages will be happening (IPCC 2007b; SEG 2007; Stern 2006).

D. Ürge-Vorsatz $\cdot$ B. Metz $(\bowtie)$

European Climate Foundation,

Tournooiveld 4,

2511 CX, The Hague, The Netherlands

e-mail: bert.metz@europeanclimate.org
The AR4 has identified the emission reductions needed to stabilize warming at certain levels (Fig. 1, IPCC 2007c). The figure demonstrates that in order to cap warming at a level such as the one defined by the European Union and the UN Scientific Expert Group on Climate Change (European Commission 2007; SEG 2007), i.e. at $2 \mathrm{C}$ above pre-industrial levels, the task is huge. In order to stay below this temperature level, global $\mathrm{CO}_{2}$ emissions will need to peak before 2015 , and they will need to be reduced by $50-85 \%$ of their 2000 levels by 2050 (see Fig. 1), as compared to the $25-90 \%$ increase projected for 2030 if no further climate measures are taken (IPCC 2007c). Even to meet a $2.4-2.8^{\circ} \mathrm{C}$ warming target level, they still need to be reduced by $30-60 \%$.

When one considers the significant challenges governments have gone through in order to meet their $0-8 \%$ reduction targets as mandated by the Kyoto Protocol, reductions in the order of $50-85 \%$ seem undoable at first sight. However, another very important finding of the Fourth Assessment report is that "the range of stabilization levels assessed can be achieved by deployment of a portfolio of technologies that are currently available and those that are expected to be commercialized in coming decades". The reason is that over a period of 40 years replacing the existing energy supply infrastructure with low carbon energy sources and a large part of the transportation system, building stock and industrial equipment with highly efficient alternatives is feasible, while short term changes are much more difficult 
Table SPM.5: Characteristics of post-TAR stabilization scenarios [Table TS 2, 3.10]

\begin{tabular}{|c|c|c|c|c|c|c|c|}
\hline Category & $\begin{array}{c}\text { Radiative } \\
\text { forcing } \\
\left(\mathrm{W} / \mathrm{m}^{2}\right)\end{array}$ & $\begin{array}{c}\mathrm{CO}_{2} \\
\text { concentrationc) } \\
(\mathrm{ppm})\end{array}$ & $\begin{array}{c}\mathrm{CO}_{2} \text {-eq } \\
\text { concentrationc) } \\
(\mathrm{ppm})\end{array}$ & $\begin{array}{c}\text { Global mean temperature } \\
\text { increase above pre- } \\
\text { industrial at equilibrium, } \\
\text { using "best estimate" } \\
\text { climate sensitivityb), c) } \\
\left({ }^{\circ} \mathrm{C}\right)\end{array}$ & $\begin{array}{c}\text { Peaking } \\
\text { year for } \mathrm{CO}_{2} \\
\text { emissions }\end{array}$ & $\begin{array}{c}\text { Change in global } \\
\mathrm{CO}_{2} \text { emissions in } \\
2050 \\
(\% \text { of } 2000 \\
\text { emissions })^{\text {d) }}\end{array}$ & $\begin{array}{c}\text { No. of } \\
\text { assessed } \\
\text { scenarios }\end{array}$ \\
\hline 1 & $2.5-3.0$ & $350-400$ & $445-490$ & $2.0-2.4$ & $2000-2015$ & -85 to -50 & 6 \\
\hline II & $3.0-3.5$ & $400-440$ & $490-535$ & $2.4-2.8$ & $2000-2020$ & -60 to -30 & 18 \\
\hline III & $3.5-4.0$ & $440-485$ & $535-590$ & $2.8-3.2$ & $2010-2030$ & -30 to +5 & 21 \\
\hline IV & $4.0-5.0$ & $485-570$ & $590-710$ & $3.2-4.0$ & $2020-2060$ & +10 to +60 & 118 \\
\hline V & $5.0-6.0$ & $570-660$ & $710-855$ & $4.0-4.9$ & $2050-2080$ & +25 to +85 & 9 \\
\hline VI & $6.0-7.5$ & $660-790$ & $855-1130$ & $4.9-6.1$ & $2060-2090$ & +90 to +140 & 5 \\
\hline \multicolumn{7}{|r|}{ Total } & 177 \\
\hline
\end{tabular}

a) The understanding of the climate system response to radiative forcing as well as feedbacks is assessed in detail in the AR4 WGI Report. Feedbacks between the carbon cycle and climate change affect the required mitigation for a particular stabilization level of atmospheric carbon dioxide concentration. These feedbacks are expected to increase the fraction of anthropogenic emissions that remains in the atmosphere as the climate system warms. Therefore, the emission reductions to meet a particular stabilization level reported in the mitigation studies assessed here might be underestimated.

b) The best estimate of climate sensitivity is $3^{\circ} \mathrm{C}$ [WG 1 SPM]

c) Note that global mean temperature at equilibrium is different from expected global mean temperature at the time of stabilization of GHG concentrations due to the inertia of the climate system. For the majority of scenarios assessed, stabilisation of GHG concentrations occurs between 2100 and 2150 .

d) Ranges correspond to the $15^{\text {th }}$ to $85^{\text {th }}$ percentile of the post-TAR scenario distribution. $\mathrm{CO}_{2}$ emissions are shown so multi-gas scenarios can be compared with $\mathrm{CO}_{2}$ only scenarios.

Fig. 1 Emission reduction needs in order to meet climate stabilization targets. (Source: IPCC 2007c, Table SPM 5)

\section{The role of improved energy efficiency in climate change mitigation, as analysed in the Fourth Assessment Report}

In its various sections, AR4 has demonstrated that improved energy efficiency will play a key role in our mitigation task. In the following paragraphs, we summarise the evidence AR4 has portrayed about the importance of improved efficiency.
The reduction of energy intensity has played a key role in reducing society's $\mathrm{CO}_{2}$ emissions over the last three decades, with the largest role in the last decade of the last century (Fig. 2). It can be expected that this will continue to play a vital role during the next three decades even without significant climate policy. However in the absence of ambitious policies, the growth in income per capita and population, potentially combined with increasing carbon intensity, will

Fig. 2 Decomposition of global energy-related $\mathrm{CO}_{2}$ emission changes at the global scale for three past and three future decades. (Source: IPCC 2007c, Fig. TS 3)

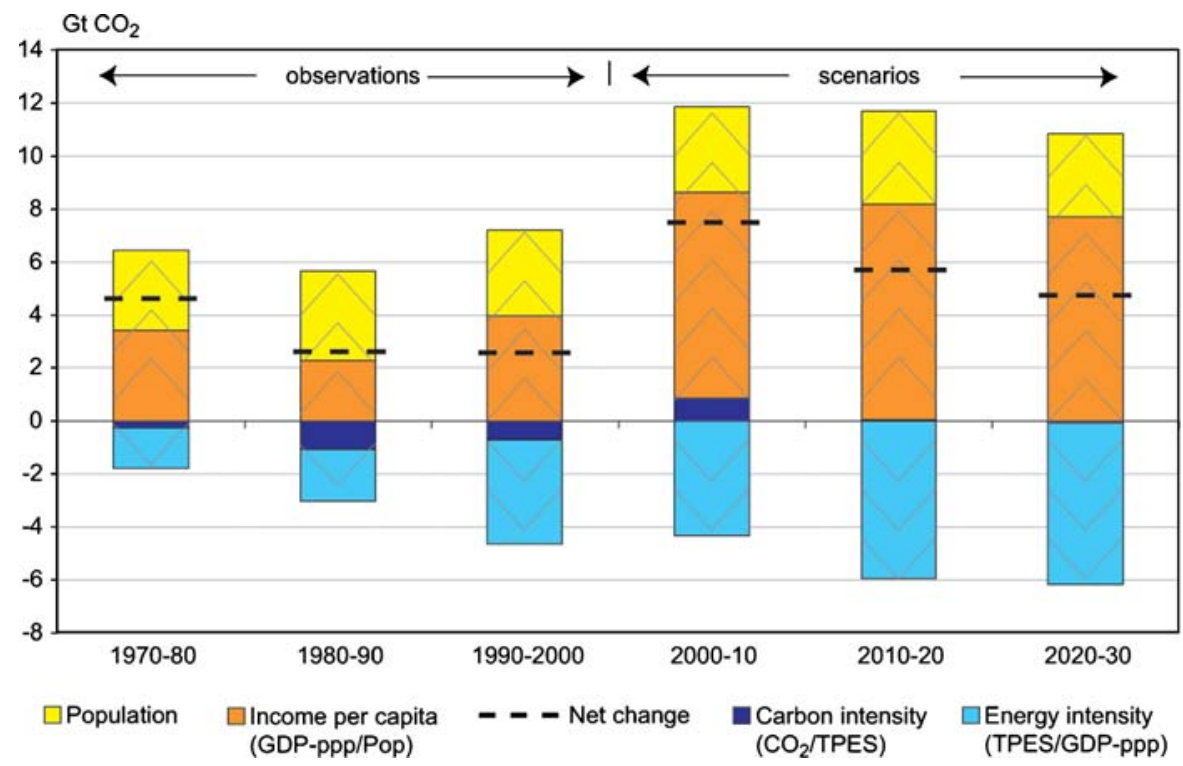


outweigh the improvement in energy intensity. While many factors contribute to the change in energy intensity (structural changes, etc.), this indicator can be used as a good proxy to suggest changes in energy efficiency too.

Beyond this business-as-usual improvement in energy efficiency, AR4 has attested that energy efficiency has a key role to play in arresting climate change. Figure 3 shows, for instance, that energy conservation and efficiency plays the second largest role in meeting climate stabilization targets in most models in the period till 2030. As the timeframe increases to a century, and as the emission reduction targets are getting more ambitious, the importance of energy efficiency is reduced as compared to options representing a decarbonised energy supply, but it still remains very important.

To get a better idea of the relative importance of improved efficiency vs. decarbonised energy, the AR4 developed a quantity called "response index". This index is derived by taking the ratio of the emission reductions in the particular scenario through improved energy efficiency and that achieved through carbon intensity reductions. Carbon intensity reductions comprise the aggregate effect of replacing fossil fuel by low carbon energy sources as well as carbon capture and storage.
Figure 4 shows how this index changes as a function of stabilization targets and over time. It shows that in the short term, energy efficiency plays the more important role, except for very low stabilization scenarios, where the contribution is about equal to that of decarbonisation. The mitigation response is shifting from energy efficiency towards reduced carbon intensity in the longer term and more ambitious climate stabilization targets. The main reason identified by AR4 behind these trends is that the costs of further efficiency improvement are expected to grow in the longer term, while those of low-carbon energy sources are projected to decrease, making this latter category more attractive.

\section{The role of energy efficiency-a sectoral appraisal}

After having shown that energy efficiency is pivotal in mitigating climate change, let's examine which sectors house the largest opportunities for efficiency improvement. One of the perhaps most frequently cited figures of the Working Group III report of AR4, SPM 6, which is shown here as Fig. 5, answers this question (IPCC 2007c). The figure identifies the economic mitigation potential in 2030 in the different sectors of the

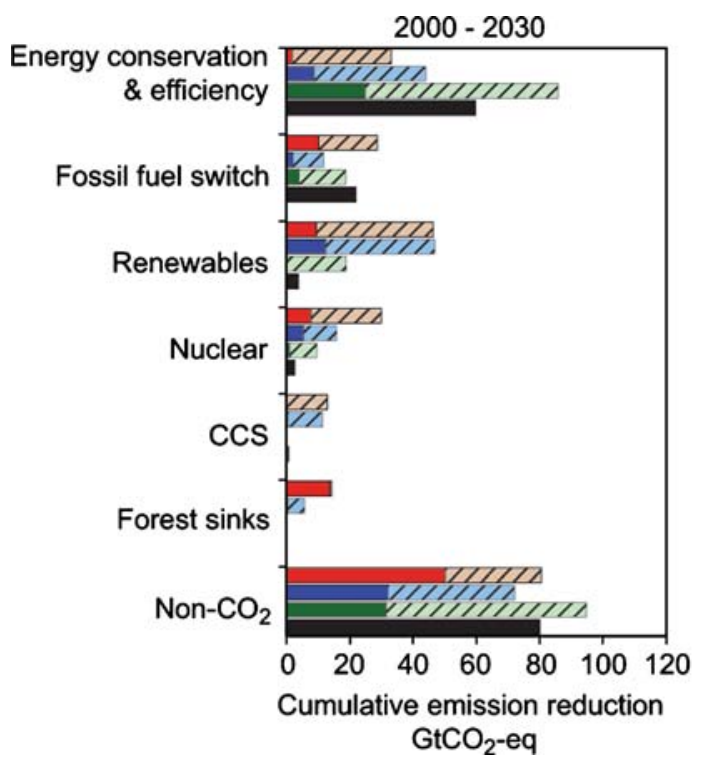

Fig. 3 Cumulative emission reductions for different mitigation measures for 2000-2030 (left-hand panel) and for 2000-2100 (right-hand panel). The figure shows illustrative scenarios from four models (AIM, IMAGE, IPAC and MESSAGE) aiming at stabilization at low (490-540 ppm $\mathrm{CO}_{2}$-eq) and intermediate
$2000-2100$

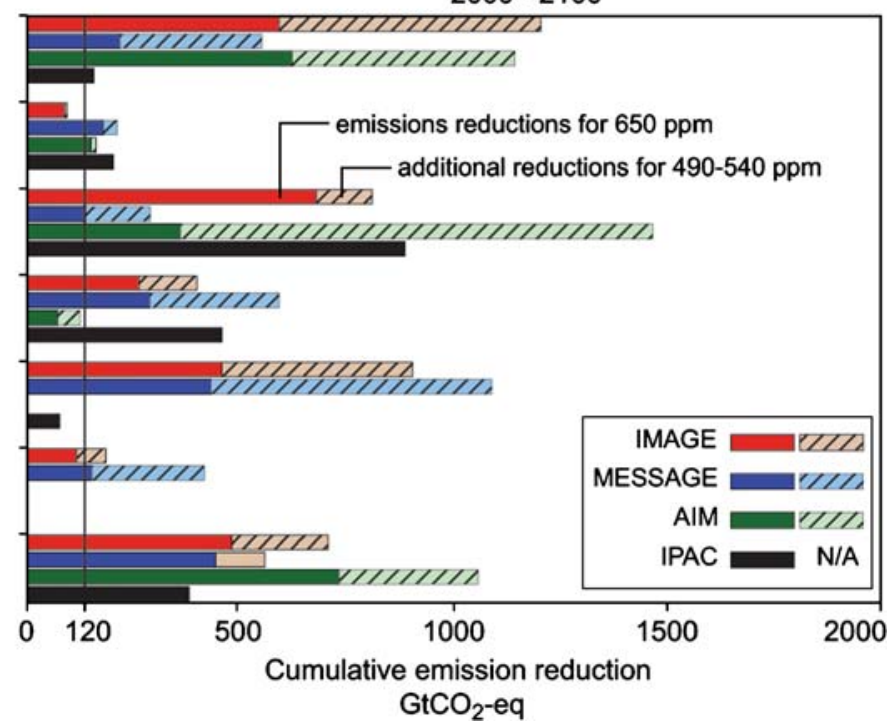

levels (650 ppm $\mathrm{CO}_{2}$-eq) respectively. Dark bars denote reductions for a target of $650 \mathrm{ppm} \mathrm{CO}_{2}$-eq and light bars the additional reductions to achieve 490-540 ppm $\mathrm{CO}_{2}$-eq. (Source: IPCC 2007c, Fig. TS 10) 


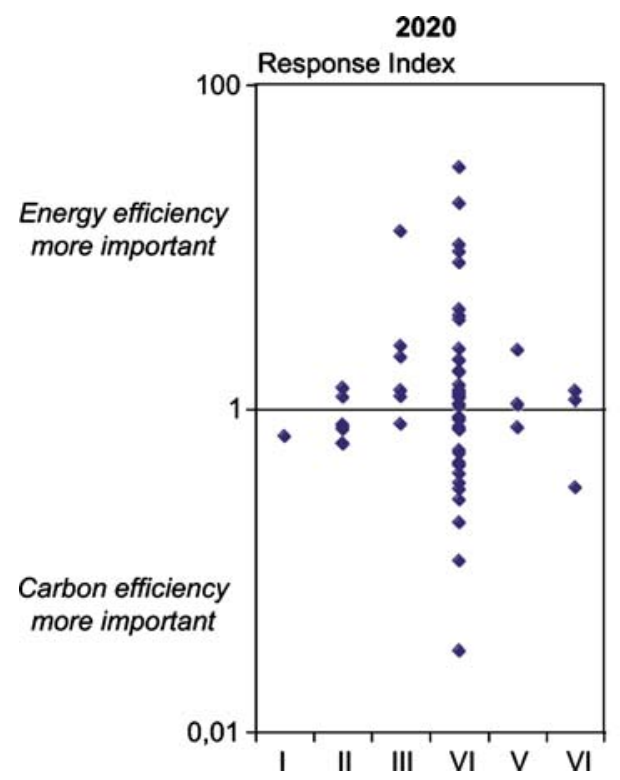

Fig. 4 Response index showing the relative importance of energy-intensity reduction (more than 1) versus carbonintensity reduction (less than 1) for post-IPCC-TAR stabilization scenarios. Note: The panels show the index for the years

economy at three different carbon price levels: under USD20/tonCO $\mathrm{O}_{2}$ equivalent, under 50, and under 100 . Buildings have the largest low-cost potential, and the vast majority of this is due to measures towards improved energy efficiency. By 2030, about 30\% of the projected GHG emissions in the buildings sector can be avoided with net economic benefit (IPCC
2050

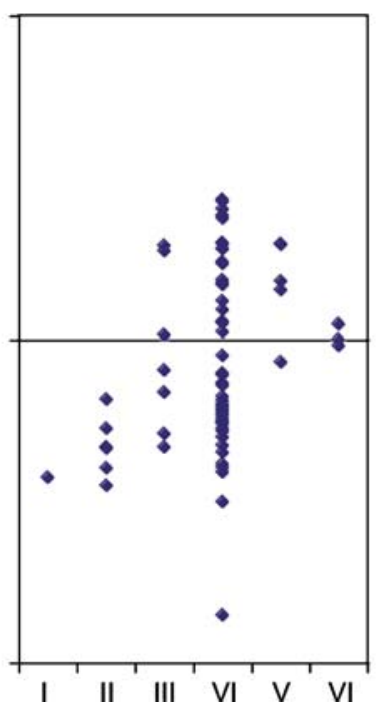

2020, 2050, and $2100(66,77$, and 59 scenarios, respectively, for which data on energy, GDP and carbon emissions were available). (Source: IPCC 2007c, Fig. 3.21)

2007c, SPM). Other sectors where efficiency can play an important role are transport and industry, these also have sizable opportunities for low-cost efficiency improvement. The figure demonstrates clearly that sectors where there is a large energy efficiency potential contribute an important share to low-cost mitigation opportunities.

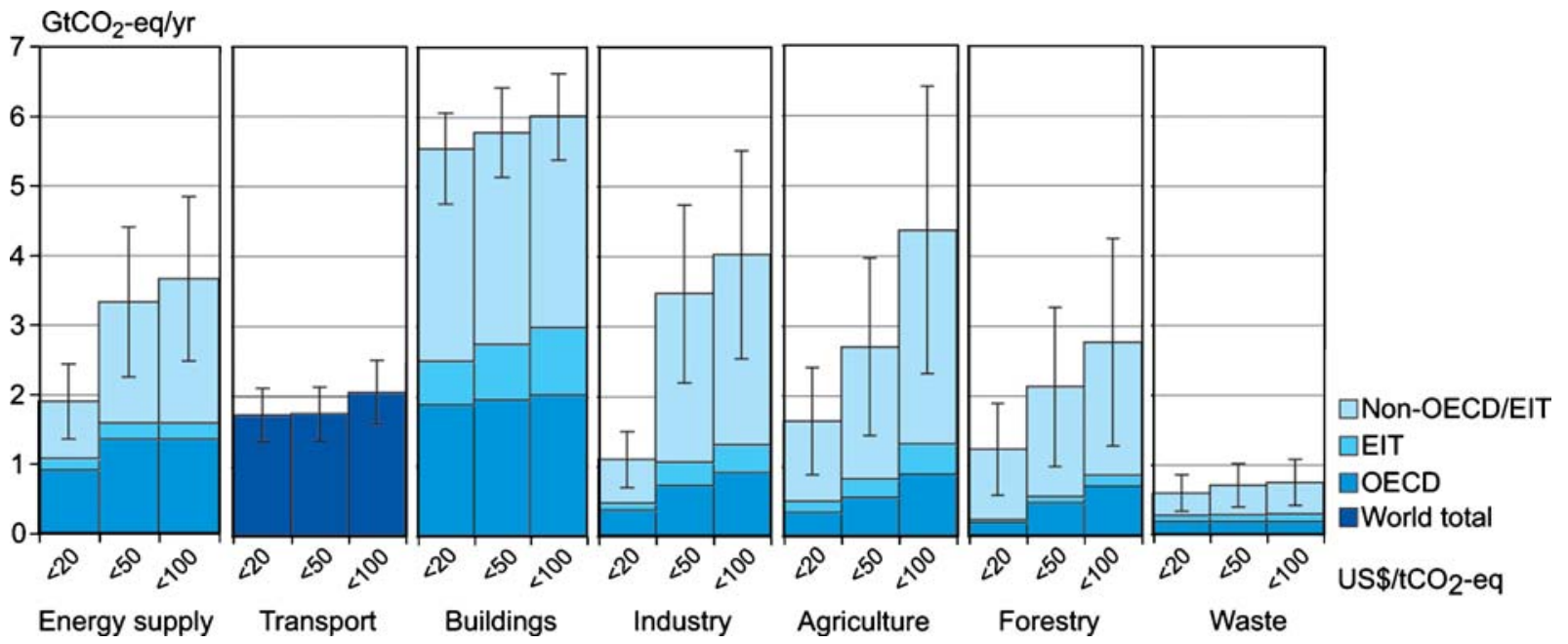

Fig. 5 Estimated sectoral economic potential for global mitigation for different regions as a function of carbon price in 2030 from bottomup studies, compared to the respective baselines assumed in the sector assessments. (Source: IPCC 2007c, Fig. SPM 6) 
The fact that there exists a large potential for negative cost energy efficiency improvement (i.e. mitigation opportunities that entail a net profit rather than a net cost) of course means that there are serious barriers for economically rational decisions to capture that potential. Indeed, many factors have been identified that act as barriers.

Figure 6 shows that negative cost potentials in the buildings sector in economies in transition are larger than those in all other sectors combined. This holds also true when mitigation opportunities costing less than USD20/ $/ \mathrm{CO}_{2} \mathrm{e}$ are considered. This is caused by subsidized energy prices maintained for long periods that prevented economically optimal levels of investments into energy efficiency. More concretely, in most of the economies in transition energy prices were heavily subsidized for decades during the communist era, resulting in a very poor building stock from an energy perspective.

\section{Co-benefits associated with mitigation through improved efficiency}

In summary, AR4 summons ample evidence that opportunities for low-cost GHG mitigation through improved energy efficiency are ubiquitous, and this is perhaps our most important lever to climate stabilization efforts in the short and medium term. For instance, if only the cost-effective mitigation investments are realized in the buildings sector, these can already supply approx. $40 \%$ of emission reduction needs by 2030 for an emission scenario that can keep the world on track to cap warming at $3^{\circ} \mathrm{C}$.

However, beyond the direct benefits of mitigating climate change through improved energy efficiency (i.e. the reduced $\mathrm{CO}_{2}$ emissions and the direct financial gains through reduced energy bills), the indirect benefits, i.e. co- and ancillary benefits, are also important. While these benefits are typically only identified qualitatively and do not make it into costbenefit analysis based decision frameworks, their total financial benefits to society can amount to significant values. AR4 highlights that, for instance, these benefits in the buildings sector can often amount to a larger sum than the direct energy benefits (IPCC 2007c, Chapter 6).

Co-benefits related to mitigation through improved energy efficiency are ample and wide-ranging. Important co-benefits for developing countries include a contribution to the alleviation of poverty. Providing access to highly energy-efficient devices and housing that con-

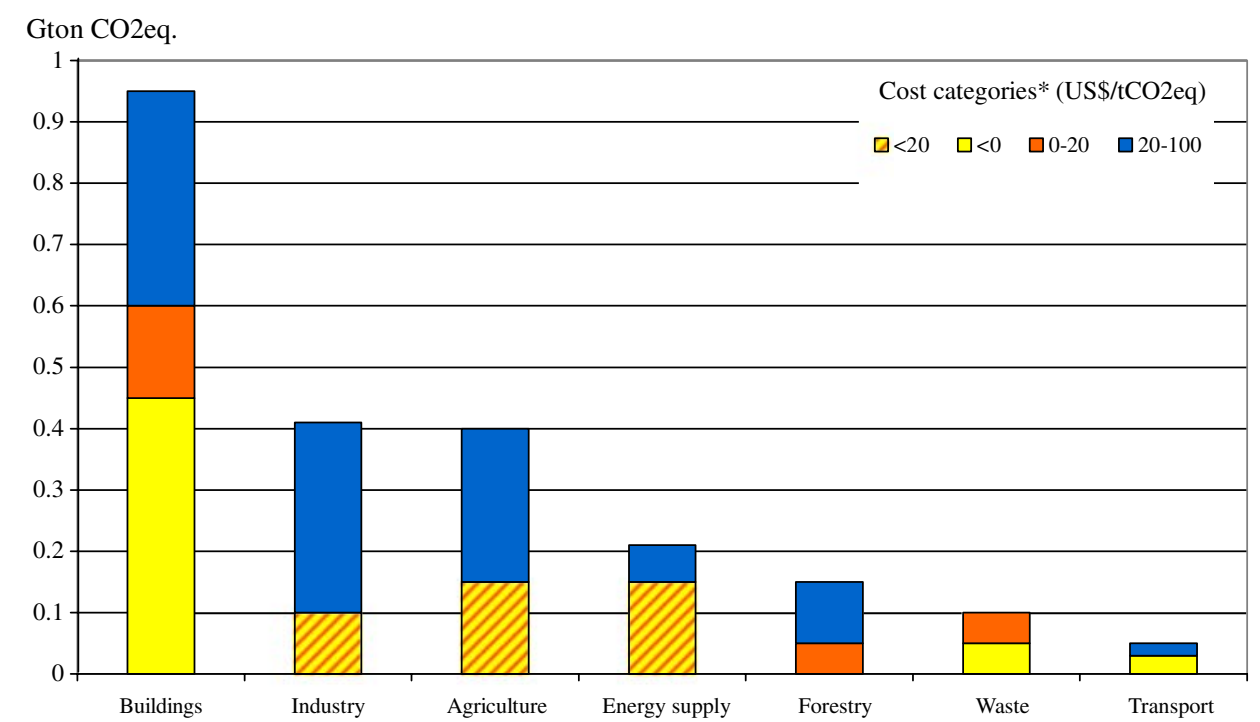

*For the buildings, forestry, waste and transport sectors, the potential is split into three cost categories: at net negative costs, at 0-20 $\mathrm{US} \$ / \mathrm{tCO} 2$, and 20-100 US\$/tCO2. For the industrial, forestry, and energy suppy sectors, the potential is split into two categories: at costs below $20 \mathrm{US} \$ / \mathrm{tCO} 2$ and at 20-100 US\$/tCO2.

Fig. 6 Sectoral GHG mitigation potential as a function of carbon cost in economies in transition in 2030. (Calculated based on IPCC 2007c, Table 11.3.) 
sumes only the minimum energy required to achieve thermal comfort reduces the need for energy payments and purchases. This allows poor people to afford a higher level of energy services than if using inefficient basic appliances or housing with poor thermal characteristics.

In transition economies, investments into improved efficiency, especially in the building stock, can help reduce the burden of increasing energy prices and the result of the removal of energy subsidies over the last two decades. If buildings use $15-25 \mathrm{kWh} / \mathrm{m}^{2} /$ year energy for providing thermal comfort (as is achievable in most temperate climates through retrofit as well as new construction) instead of $180-250 \mathrm{kWh} / \mathrm{m}^{2} /$ year prevailing in the building stock of transition economies, this can substantially contribute to the increase in social welfare.

Energy poverty occurs not only in developing countries and economies in transition, but also in developed ones. Fuel poverty, or the inability to afford basic energy services to meet minimal needs or comfort standards, is found in even the wealthiest countries. In the UK in 1996 , about $20 \%$ of all households were estimated to live in fuel poverty. The number of annual excess winter deaths, estimated by the UK Department of Health at around 30,000 annually between 1997 and 2005 , can largely be attributed to inadequate heating (Boardman 1991; DoH 2000). Improving energy efficiency in these homes is a major component of strategies to eradicate fuel poverty.

Beyond the social co-benefits, there is a broad spectrum of further benefits associated with mitigation through improved efficiency. For instance, improvements in industrial energy efficiency help increase productivity and thus international competitiveness. Providing energy "supply" through improving end-use efficiency is often a more cost-effective way for "capacity expansion", and often has a positive effect on employment, even if potential layoffs are considered in the energy supply industries. The employment benefits arise directly by creating new business activities in efficiency improvement and indirectly through the economic multiplier effects of spending the money saved on energy costs in other ways. The European Commission (European Commission 2005) estimates that a $20 \%$ reduction in EU energy consumption by 2020 can potentially create (directly and indirectly) as many as one million new jobs in Europe, especially in the area of semi-skilled labour in the building sector (Jeeninga et al. 1999; European Commission 2003).
Providing energy efficiency services through energy service companies (ESCOs) has also proven to be a lucrative business opportunity. Experts estimate a market of $€$ 5-10 billion in Europe (Butson 1998).

Significant reductions in energy demand (such as through the renovation of the building stock or other efficiency opportunities) can ease energy import dependence, and thus help improve energy security-also featuring as a key policy goal in most national and international energy strategies. Other co-benefits of mitigation through improved efficiency include the increased value of the real estate and building stock (IPCC 2007c, Chapter 6); reduced local and global air pollution; reduced vulnerability to weather extremes (in well insulated buildings); improved health, quality of life and comfort; reduced noise in transport (IPCC 2007c, Chapter 5). In industry co-benefits arise through reduced emissions of pollutants and waste production (which in turn reduce environmental compliance and waste disposal costs), increased production and product quality, reduced maintenance and operating costs, an improved working environment, and other benefits such as decreased liability, improved public image and worker morale, and delaying or reducing capital expenditures (IPCC 2007c, Chapter 7).

\section{The rationale, aim and the process of the special issue}

The previous sections summarized what role IPCC has attributed to improved energy efficiency in climate change mitigation in its Fourth Assessment Report. However, this is a document that has to concisely cover a very broad range of issues, and thus a wide spectrum of details, case studies and analyses that substantiate the above points in more detail could not be included in the report due to space constraints. During the writing process a rich body of literature was assessed by the authors of AR4 that provides further insights regarding the main points of the IPCC assessment. Some of this material was considered worth to be published.

Therefore the aim of this special issue is to provide further evidence, case (country) studies and substantiation for the various conclusions of AR4 as they pertain to the role of improved energy efficiency in climate change mitigation. In addition to providing further details, another important role of the special issue is to update some of the information in AR4 and 
review the most recent developments in the field. Since much of the writing for AR4 was completed by mid 2006, the publication of this special issue in 2009 allows for an update of the knowledge in the field of energy efficiency and climate change. This could be valuable for the conceptualization and implementation of the Fifth IPCC Assessment Report. This special issue also highlights important gaps in knowledge that would be important to be filled, or at least attempted to be narrowed, so that the next IPCC assessment report can benefit from that.

All lead authors of Working Group III of the Fourth Assessment Report were offered the opportunity to contribute papers. This generated overwhelming interest: a total of 29 abstracts were submitted from 76 authors. ${ }^{1}$ The result is two volumes of this special issue.

\section{Highlights of Volume 1 of the special issue}

The first volume of the special issue focuses on the role of energy efficiency in climate change scenarios, sectoral assessment, and country case studies, primarily providing detail about sectoral analyses.

Hanaoka et al. analyze the role of energy intensity improvement in the short term (to the year 2020) and mid term (to the year 2050) in the context of longterm greenhouse gases (GHG) stabilization scenarios. They provide more detail than what the AR4 has given, including for major GHG-emitting countries, such as the USA, Western Europe, China, and India. One finding is that energy intensity improvement plays an important role in the period till 2020 (similar to the AR4 findings), and the rate of energy intensity improvement generally is around $2 \%$ /year as a global median value across the low stabilization categories I-III in the period till 2050.

The industrial sector, analyzed by Worrell in his paper on energy efficiency in industry, contributes about $37 \%$ of the global greenhouse gas emissions. In the near future, energy efficiency is potentially the most important and cost-effective means for mitigating greenhouse gas emissions from industry. This paper discusses the potential contribution of industrial energy efficiency technologies and policies to reduce energy use and

\footnotetext{
${ }^{1}$ The majority, but not all 76 authors are lead authors of IPCC, but all abstracts submitted were led by an IPCC lead author or coordinating lead author.
}

greenhouse gas emissions to 2030. It concludes that the total potential for GHG emission mitigation in the industrial sector by 2030 is in the range of $10-40 \%$ for a range of baseline scenarios. However, the author notes that various uncertainties render it difficult to make a comprehensive worldwide estimation of energy efficiency potentials for this sector.

Another sector with particularly high GHG emissions levels is transportation. In their paper on energy efficiency technologies for passenger vehicles, Kobayashi et al. assess potentials for improving fuel efficiency and conclude that technology development can achieve as high as $50 \%$ increase in fuel efficiency of gasoline and diesel vehicles by 2035 to 2050 . Hybrid electric and plug-in hybrid vehicles can bring this up to $70-80 \%$. In congested traffic, vehicles have much higher emissions than their test values suggest. Reducing congestion is therefore an important contribution to achieving higher fuel efficiency. An additional 5-20\% can be obtained from an increase in the operating efficiencies of vehicles, such as more efficient replacement tires, eco-driving, better traffic management, etc.

Harvey concludes that utilizing existing technologies may potentially result in significant reductions of energy use in buildings. Provision of a high-performance building envelope is the single most important factor in the design of low-energy buildings, not only because it reduces the heating and cooling loads that the mechanical system must satisfy, but also because it permits alternative (and low carbon) systems for meeting the reduced loads. The savings available through better and alternative energy-using systems (heating, ventilation, cooling, and lighting) are generally much larger than the savings that can be achieved by using more efficient devices (such as boilers, fans, chillers, and lamps). Because improved building envelopes and improved building systems reduce the need for mechanical heating and cooling equipment, buildings with dramatically lower energy use (50-75\% savings) often entail no greater construction cost than conventional design, while yielding significant annual energy cost savings.

In their case study on Brazil's household sector, Shaeffer et al. demonstrate significant electricity and $\mathrm{CO}_{2}$ reduction potentials of about $20 \%$ at zero or negative cost. This was calculated with a $10 \%$ rate of return on investment, which is higher than what was used in the IPCC AR4 estimates of $30 \%$ by 2030 on average globally. 
Research on Japan's building sector by Murakami et al. shows that there are many commercially available low-cost ways of reducing energy consumption and $\mathrm{CO}_{2}$ emissions. Interestingly, behavioural changes that cut down energy use, such as setting inside temperatures in homes and offices are taken very seriously in Japan and active campaigns have been launched by the government. There is a recommendation to set minimum temperatures of $28^{\circ} \mathrm{C}$ in summer in office buildings and there are so called "cool-biz" campaigns, suggesting office staff do not wear ties but comfortable summer clothing. $\mathrm{CO}_{2}$ emissions in 2050 can be reduced by $60 \%$ compared to 1990 levels, if all these energy saving measures are implemented.

Contribution of energy efficiency measures in the agricultural sector to climate change mitigation is under-researched. Gallaher et al. make an attempt to fill this gap by estimating the $\mathrm{CO}_{2}$ mitigation potential achievable through energy efficiency options in USA agriculture. The largest sources of energy use in the sector were identified as motors used in irrigation systems or other pumping operations; farm machinery such as tractors used in daily farm operations; and space conditioning, such as HVAC systems for livestock and crop drying systems. They show that the sector is, potentially, a source of $25 \%$ emissions reductions from fuel use at negative costs and point to the need for policies to capture this potential.

Another piece of research on the agricultural sector, performed by Schneider et al., reinforces this conclusion and extends it to the global level. They conclude that roughly about 500 million tons of $\mathrm{CO}_{2}$ emissions reduction can result from implementation of available technologies and energy efficiency measures at zero or negative cost today. This means that the overall economic potential of reductions in the agricultural sector could be at least 30\% higher than the IPCC AR4 indicated. There is however a risk of double counting of agricultural sector measures and overlaps with measures in the building and transport sector.

In volume two of the special issue (to be published in a subsequent issue), the focus will be on a broader set of issues regarding energy efficiency, such as the relation with sustainable development policies.

\section{References}

Boardman, B. (1991). Fuel poverty: from cold homes to affordable warmth. London: Belhaven Press.

Butson, J. (1998). The potential for energy service companies in the European Union. In Proceedings of the First International Conference on Improving Electricity Efficiency in Commercial Buildings, Amsterdam.

Department of Health (DoH) (2000). Fuel poverty and health. Circular from the UK Department of Health. Available at www.dh.gov.uk/assetRoot/04/01/38/47/04013847.pdf.

European Commission (2003). Proposal for a Directive of the European Parliament and of the Council on energy enduse efficiency and energy services. Brussels: Commission of the European Communities.

European Commission (2005). Green paper on energy efficiency: Doing more with less. Luxembourg: Office for Official Publications of the European Communities.

European Commission (2007). Limiting Global Climate Change to 2 degrees Celsius: The way ahead for 2020 and beyond. Brussels: Communication from the Commission to the Council, the European Parliament, the European Economic and Social Committee and the Committee of the Regions. Commission of the European Communities.

IPCC (2007a). Climate Change 2007: The Physical Science Basis. Contribution of Working Group I to the Fourth Assessment Report of the Intergovernmental Panel on Climate Change. Cambridge: Cambridge University Press.

IPCC (2007b). Climate Change 2007: Impacts, Adaptation and Vulnerability. Contribution of Working Group II to the Fourth Assessment Report of the Intergovernmental Panel on Climate Change. Cambridge: Cambridge University Press.

IPCC (2007c). Climate Change 2007: Mitigation of Climate Change. Contribution of Working Group III to the Fourth Assessment Report of the Intergovernmental Panel on Climate Change. Cambridge: Cambridge University Press.

Jeeninga, H., Weber, C., Mäenpää, I., García, F. R., Wiltshire, V., \& Wade, J. (1999). Employment impacts of energy conservation schemes in the residential sector. Calculation of direct and indirect employment effects using a dedicated input/output simulation approach. Petten: Energy Research Centre of the Netherlands.

Scientific Expert Group on Climate Change (SEG) (2007). Confronting Climate Change: Avoiding the Unmanageable and Managing the Unavoidable. Report prepared for the United Nations Commission on Sustainable Development. Sigma Xi, Research Triangle Park, NC, and the United Nations Foundation, Washington, DC. Available online at www.globalproblems-globalsolutions-files.org/ unf_web site/PDF/climate $\% 20$ _change_avoid_unmanagable_mana ge_unavoidable.pdf.

Stern, N. (2006). The Economics of Climate Change: The Stern Review. Cambridge: Cambridge University Press. 